A.Kurita, T. Shibuya, K. Isojima,K.Arakawa, K. Mizuno, S.Kondo, K. Satomura,H.Sugawara, H.Nakamura.

National Defense Medical. College, Saitama-ken Tokorozawa, 359

We investigated the changes of coronary sinus bl ood flow(CSBF) and myocardial oxygen consumption ( $\mathrm{MVO}_{2}$ ) before and during anginal. pain( $\mathrm{AP}$ ) and to find the correlations between these parameters with indices of myocardial oxygen consumptions in 13 chronic stable angina who could provoke AP by bicycle ergometer. Brachial arterial.(BA) pressure was obtained by an Amplatz needle and CSBF was measured by thermodilution technique. Bloods were sampled from both BA and CS to calculate MVO, Coronary vascular resistance(CVR) was calculated by the formula of mean BAP/CSBF. When AP were provoked CSBF was decreased from $206 \pm 56 \mathrm{ml} / \mathrm{min}$ (mean SD) to $183 \pm 67(\mathrm{NS}, \mathrm{n}=10$ ) and MVO was decreased from $24.3 \pm 7.5 \mathrm{mmHg} / \mathrm{min}$ to $20.6 \pm 8.6 \quad(p<0.05, n=8)$, whereas CVR was increased from $0.63 \pm 0.17 \mathrm{mmHg} / \mathrm{ml} /$ min to $0.74 \pm 0.18(p<0.01, n=10)$ and pressure rate product(PRP) was increased from $242 \pm 36 \mathrm{mmHg}^{\circ}$ bpmiü to $256 \pm 48(\mathrm{NS}, n=9)$. Correlations of CSBF with MVO at all determinations was $0.87(\mathrm{p}<0.01, n=72)$, with ${ }^{2}$ PRP was 0.86 and with HR $x$ mean BA was 0.70 , wherePRP was 0.86 and with $\mathrm{HR} x$ mean $B A$ was 0.70 , whe
as correlations of MVO, with PRP was 0.67 and $4 R x$ mean BA was $0.69 .{ }^{2}$ These data suggested that (1) during angina, reduction of Mvo, and increment of CVR were more remarkably changed than CSBF and PRP, (2) lower values of correlations between $\mathrm{CSBF}$ and $\mathrm{MVO}_{2}$ with indices of $\mathrm{MVO}_{2}$ comparing with previous reporters were prebably gue to the difference of coronary bed anatomy.

\section{$-17-$ \\ ROLE OF ADENOSINE IN REGULATION OF CORONARY BLOOD FLOW IN PATIENTS WITH EFFORT ANGINA}

Masayoshi Mishima, Masatsugu Hori, Jun Tamai, Masafumi Kitakaze, Yukihiro Koretsune, Kunimitsu Iwai, Katsuomi Iwakura, Michitoshi Innue, Takenobu Kamada, Shinsuke Nanto*, Kazuhisa Kodama*

Osaka University Medical School

*Osaka Police Hospital

To test the hypothesis that adenosine plays a pivotal role in the regulation of coronary blood flow at rest and during increased myocardial oxygen demand in coronary artery disease, adenosine release (ADR) into the coronary vein was determined at rest and during rapid atrial pacing in 14 patients (pts) with effort angina (EA), who had severe narrowings in the LAD artery. Seven pts with normal coronary arteriograms were also studied as the controls. The great cardiac venous flow (GCF, thermodilution), lactate extraction and ADR were determined before and during pacing. In resting state, the average $\operatorname{ADR}(1.93 \pm .29 \mathrm{n} \mathrm{mol} /-$ min, + SE) in pts with EA was significantly higher than that $(.27 \pm .29 \mathrm{n} \mathrm{mol} / \mathrm{min})$ in controls. During pacing, ADR increased in the pacing-rate dependent manner in both groups. However, ADR in pts with EA was significantly higher at any pacing rate, although increases in GCF were not significantly different. At maximal pacing, which induced anginal pain and lactate production, a marked ADR was observed $(8.70+1.87 \mathrm{n} \mathrm{mol} / \mathrm{min})$. In 9 pts who underwent PTCA, ADR decreased $(p<.01)$ both at rest and during pacing. These results indicate that in patients with severe coronary narrowings, adenosine plays a major role in the regulation of coronary blood flow both at rest and when increased myocardial oxygen demand.

\section{$-18-$ \\ RELEASE OF ADENOSINE AND LACTATE FROM THE HEART DURING ATRIAL PACING IN PATIENTS WITH ISCHEMIC HEART DISEASE}

\author{
Takashi Haneda, Junichi Kato, Hirohisa \\ Yamashita, Katsuyuki Tobise, Sokichi \\ Onodera, Kazuo Ichihara , Yasushi Abiko* \\ First Department of Internal Medicine and \\ Department of Pharmacology, Asahikawa \\ Medical College, Asahikawa, Japan
}

In patients with coronary stenosis, an increase in oxygen demand produces anginal pain and release of lactate from the heart. Animal experiments have revealed that myocardial ischemia caused release of adenosine as well. Therefore, we examined whether human hearts with coronary stenosis release adenosine during angina induced by atrial pacing. Patients who were diagnosed or doubted as having ischemic heart disease were subjected to routine cardiac catheterization. The patients were divided into three groups, groupI: patients without coronary stenosis, who had no anginal pain even after pacing; groupII: patients without coronary stenosis having anginal pain on pacing; and groupIII: patients with coronary stenosis having anginal pain on pacing. In groupI, there was no significant release of adenosine and lactate during pacing, although heart rate was increased by pacing from 74.5 to 150.0 beats/min. In groupII, heart rate was increased by pacing from 71.6 to 144.4 beats/min. Adenosine and lactate were released but insignificantly. In group III, pacing increased heart rate from 66.1 to 130.0 beats/min, and produced release of adenosine and lactate significantly, the release of adenosine being more marked than that of lactate. In conclusion, human hearts with coronary stenosis release a significant amount of adenosine and lactate during pacing-induced angina.

\section{$-19-$ \\ INTRAOPERATIVE MEASUREMENT OF MYO- CARDIAL BLOOD FLOW BY ELECTROLYTIC HYDROGEN GAS CLEARANCE METHOD}

Fumio Kawajiri, Michio Kawasuji, Takekazu Aoyama, Naoki Sakakibara

Department of Surg (I), School of Medicine Kanazawa University

We have measured MBF by electrolytic hydrogen gas clearance method intraoperatively and evaluate the effect of coronary revascularization.

Seventeen cases with IHD (AP:OMI $=10: 7$ ) and 8 with non-IHD as control are studied. MBF measurenent was performed before and after cardiopulmonary bypass at the $L V$ ant. wall (LAD region) and $R V$ ant. wall.

MBF of non-IHD group was $176 \pm 27 \mathrm{ml} / \mathrm{min} / 100 \mathrm{gr}$ and non-ischemic area (under $75 \%$ stenosis) of IHD group was $186 \pm 48 \mathrm{ml} / \mathrm{min} / 100 \mathrm{gr}$. Whearas MBF of ischemic area (over $75 \%$ stenosis) was $131 \pm$ $100 \mathrm{ml} / \mathrm{min} / 100 \mathrm{gr}$, which was significantly low (p 0.05). Preoperative $\mathrm{MBF}$ at $\mathrm{LAD}$ region with or without $\mathrm{OMI}$ was $80 \pm 55 \mathrm{ml} / \mathrm{min} / 100 \mathrm{gr}$ and $157 \pm 52 \mathrm{ml} / \mathrm{min} / 100 \mathrm{gr}$. Severity of LAD stenosis and $\mathrm{MBF}$ was evaluated. In $75 \%$ stenosis $\mathrm{MBF}$ of $195 \pm 40 \mathrm{ml} / \mathrm{min} / 100 \mathrm{gr}$ was ob- 